\title{
ANALISIS MENU UNTUK MENENTUKAN STRATEGI BAURAN PEMASARAN PADA BUNUT CAFÉ DI HOTEL WHITE ROSE LEGIAN KUTA
}

\author{
Dewa Ayu Suryawati ${ }^{1}$, Rosvita Flaviana Osin² \\ Akademi Komunitas Manajemen Perhotelan Indonesia \\ Suryawati_dewaayu@yahoo.co.id'1 osinanggal@yahoo.co.id²
}

\begin{abstract}
Abstrak
Perkembangan industri pariwisata baik berupa hotel, restoran, dan tempat-tempat rekreasi lainnya turut mengiringi perkembangan pariwisata di Bali. Banyaknya industri pariwisata yang berkembang khususnya restoran, menimbulkan persaingan semakin ketat. Semua pelaku industri restoran menginginkan pertumbuhan dan perkembangan dalam usahanya. Untuk mencapai tujuan tersebut, salah satu yang bisa dilakukan adalah menganalisis menu yang dijual untuk menentukan strategi bauran pemasaran sehingga dapat mencapai keuntungan yang diinginkan secara optimal. Tujuan dari penelitian ini adalah untuk mengetahui dan memaparkan tingkat popularitas dari menu a'la carte untuk lunch dan dinner serta menentukan strategi buaran pemasaran apa yang harus diambil oleh pihak manajemen hotel.

Dalam penelitian ini digunakan data kualitatif dan kuantitatif yaitu data-data yang berupa informasi dan angka-angka dari data intern dan ekstern. Data ini dikumpulkan dan diolah dengan teknik analisis menu engineering. Hasil dari penelitian ini menunjukan bahwa dari keseluruhan a'la carte menu yang ditawarkan pada Bunut Café dari 74 makanan , 29,73\% atau 22 item tergolong menu Star (popular dan menguntungkan), $25.68 \%$ atau 19 item menu tergolong kelas menu Plowhorse (popular tetapi tidak menguntungkan), $28.38 \%$ atau 21 item tergolong kelas menu Puzzle (tidak popular tetapi menguntungkan), $16.22 \%$ atau 12 item tergolong kelas menu Dog (tidak popular dan tidak menguntungkan).
\end{abstract}

Kata kunci: Analisis Menu, Strategi, Bauran Pemasaran

\begin{abstract}
The development of the tourism industry in the form of hotels, restaurants and other recreational places has also accompanied the development of tourism in Bali. The number of tourism industries that have developed, especially restaurants, has led to increasingly fierce competition. All restaurant industry players want growth and development in their business. To achieve this goal, one that can be done is to analyze the menu being sold to determine the marketing mix strategy so that it can achieve the desired benefits optimally. The purpose of this study was to find out and describe the popularity level of the a la carte menu for lunch and dinner and determine what marketing strategy to take by the hotel management.

In this study used qualitative and quantitative data, namely data in the form of information and numbers from internal and external data. This data is collected and processed by engineering menu analysis techniques. The results of this study indicate that from the overall a'la carte menu offered on Bunut Café from 74 meals, $29.73 \%$ or 22 items classified as Star (popular and profitable), $25.68 \%$ or 19 menu items classified as the Plowhorse (popular but not profitable), $28.38 \%$ or 21 items belonging to the Puzzle menu class (unpopular but profitable), $16.22 \%$ or 12 items classified as the Dog menu class (unpopular and unprofitable).
\end{abstract}

Keywords: Menu Analysis, Strategy, Marketing Mix 
Jurnal Manajemen Pelayanan Hotel Akademi Komunitas Manajemen Perhotelan Indonesia (Suryawati \& Osin, halaman 29-35) Vol 3, No 1 Edisi Juni 2019

\section{PENDAHULUAN}

Sektor pariwisata terus digalakkan karena sektor ini merupakan andalan dalam menghasilkan pendapatan masyarakat serta devisa bagi negara. Seiring dengan pembangunan dan pertumbuhan ekonomi, peranan pariwisata dewasa ini semakin meningkat sebagai sektor baru penyumbang devisa yang cukup besar bagi peningkatan kesejahteraan masyarakat (Joko, 2014). Bali memiliki potensi wisata yang menarik didukung oleh panorama dan kebudayaan asli yang membuat Pulau Bali masuk dalam daftar destinasi terbaik dari tujuan wisata popular lainnya di seluruh dunia. Increasing numbers of tourists who come to Bali opens the opportunity for the local people to work in tourism object (Anggayana, Nitiasih, Budasi, 2016).

Situasi ini dimanfaatkan oleh pelaku industri atau penyedia jasa sebagai peluang dalam membangun usahanya, baik disektor usaha perhotelan, spa, kuliner, pusat oleh-oleh dan sebagainya. White Rose Hotel adalah salah satu hotel menengah dikawasan Legian Kuta yang juga memiliki restoran sebagai salah satu sumber pendapatannya yang menawarkan berbagai produk atau item menu. Banyaknya jenis makanan yang tersedia di dalam menu yang ditawarkan, secara otomatis dapur mempersiapkan banyak jenis makanan sesuai dengan variasi makanan yang terdaftar dalam menu. Dari menu tersebut kita bisa mengidentifikasi kebutuhan dan keinginan konsumen. Berdasarkan menu, penyedia jasa restoran dapat dapat melakukan forecasting pembelian bahan baku serta biaya yang akan dikeluarkan. Rabone (2007:79) mengatakan " $A$ good menu is a menu that can generate profit and popularity". Indikasi tersebut dapat diketahui dari tingginya tingkat penjualan yang dihasilkan kepada restoran.

Dalam berwisata sudah tentu wisatawan tersebut ingin dilayani serta mendapatkan akomodasi yang layak sesuai dengan apa yang diharapkan wisatawan masing-masing (Anggayana \& Sari, 2018). Peningkatan ini sudah tentu ditunjang oleh pelayanan yang baik, dalam pelayanan tersebut, fasilitas dan kualitas pelayanan menjadi ujung tombak dalam hal pemberian kesan baik terhadap pelayanan (Anggayana \& Sari, 2018). Untuk meraih peningkatan harusnya dibarengi dengan pendidikan. Tujuan pendidikan pada dasarnya menghantarkan para siswa menuju perubahan-perubahan tingkah laku baik intektual, moral maupun sosial agar dapat hidup mandiri sebagai makhluk individu dan makhluk sosial sehingga menghasilkan sumber daya manusia yang berkualitas (Anggayani \& Osin, 2018). Dengan berkembangnya suatu industri pariwisata akan berpengaruh kepada meningkatnya pendapatan masyarakat sekitar obyek wisata serta terciptanya lapangan kerja (Osin, Kusuma, \& Suryawati, 2019).

Menurut Sulastiyono (2004:212) membagi menu menjadi dua jenis yaitu $A^{\prime} l a$ carte menu dimana semua item makanan secara individual mempunyai harga dan tamu bisa memilih jenis makanan yang diinginkan serta menggabungkannya menjadi satu set urutan makanan sedangkan Table d'hote menu merupakan satu set makanan dengan satu harga yang sudah dipastikan sehingga tamu bisa memilih hanya makanan pembuka (appetizer) dan penutup (dessert) termasuk pilihan kopi atau teh. Identifikasi terhadap pemenuhan kebutuhan dan keinginan konsumen serta identifikasi terhadap tingkat perolehan pendapatan pada Bunut Café harus dianalisis secara regular dan terus menerus. Kotler (2007) mendefinisikan manajemen pemasaran sebagai seni dan ilmu memilih pasar sasaran dan meraih, mempertahankan serta menumbuhkan pelanggan dengan menciptakan dan mengkomunikasikan nilai pelanggan yang unggul. Sejalan dengan menumbuhkan komunkasi dengan pelanggan penguasaan bahasa Inggris juga penting, English exist as a global language, therefore English is widely regarded as global language (Anggayana, 
Nitiasih, \& Budasi, 2016). English is used in the early stages of major social and economic transition (Anggayana, Nitiasih, \& Budasi, 2016).

Hal ini membantu pihak manajemen dapat merencanakan serta mempromosikan produk atau menu yang ditawarkan. Menurut Kotler dan Keller (2017) bauran pemasaran merupakan satu perangkat yang terdiri dari produk, harga, promosi dan distribusi yang didalamnya akan menentukan tingkat keberhasilan pemasaran dan semua itu ditujukan untuk mendapatkan respon yang diinginkan dari pasar sasaran. Analisis menu bertujuan untuk mengetahui makanan-makanan mana saja yang disuka (tingkat popularitas), makanan mana saja yang bisa mendatangkan keuntungan yang maksimal dan untuk mengetahui apakah kondisi menu masih relevan untuk ditawarkan kepada tamu. Pokok permasalahan dari penelitian ini yaitu bagaimana tingkat popularitas dan tingkat keuntungan menu pada Bunut Café di Hotel White Rose Legian Kuta Bali dan bagaimana strategi bauran pemasaran apa yang tepat digunakan sesuai dengan hasil analisis menu?

\section{METODE}

Metode yang digunakan dalam penelitian ini yaitu mix method dengan data kualitatif dan kuantitatif. Data kualitatif berupa jenis menu yang ditawarkan serta data kuantitatif antara lain history of sales, food coast dan food selling price. Teknik pengumpulan data dilakukan dengan wawancara, dokumentasi dan observasi. Dalam menganalisis data menggunakan teknik analisis menu engineering. Schwartz (2006) menu engineering merupakan sebuah pendekatan yang bersifat keilmuan yang digunakan untuk mengklasifikasikan produk dalam sebuah menu ke dalam empat kategori yang dapat menentukan apa yang akan dilakukan terhadap sebuah menu untuk menghasilkan profit yang lebih.
Teknik analisis menu engineering adalah alat evaluasi untuk menganalisis menu secara matematis dan logis yang digunakan oleh manajemen agar menu yang ditawarkan lebih sesuai dengan selera atau minat calon pelanggan sehingga menu tersebut dapat lebih dikenal dan dapat memberikan keuntungan yang maksimal.

Adapun langkah-langkah di dalam menganalisis menu adalah sebagai berikut:

1. Mengidentifikasi menu. Menulis dan mengelompokkan semua nama dari menu yang muncul dari daftar menu

2. Mencatat jumlah porsi makanan yang terjual dari masing-masing menu (menu mixs)

3. Menghitung proporsi menu mixs (MM) dengan rumus:

$\mathrm{MM} \%=$ Menu item sales $\mathrm{X}$ $100 \%$

Total number sold

4. Menu Mixs percentage category (MM\% Category), presentase menu mix "MM\% achievement rate. Achievement ini ditentukan dengan mengalikan $70 \%$ dengan satu per jumlah menu yang dianalisis $(1 / \mathrm{N})$

5. Mencatat harga jual menu/Selling Price (SP)

6. Menentukan standar harga pokok makanan yang merupakan gabungan dari standar recipe cost, garnish cost dan supplemental cost

7. Menghitung Contribution Margin (CM) dengan rumus: $\mathrm{CM}=\mathrm{SP}-\mathrm{FC}$

8. Menentukan total pendapatan (total revenue) masing-masing makanan dengan rumus:

Total revenue $=$ Harga jual $\mathrm{x}$ menu mix

9. Menentukan total harga pokok (total food cost) dari masing- 
Jurnal Manajemen Pelayanan Hotel Akademi Komunitas Manajemen Perhotelan Indonesia (Suryawati \& Osin, halaman 29-35) Vol 3, No 1 Edisi Juni 2019

masing makanan dengan menggunakan rumus:

Total food cost $=$ Harga pokok $\mathrm{x}$ menu mix

10. Menentukan total contribution margin (Total $\mathrm{CM}$ ) dengan menggunakan rumus:

Total $\mathrm{CM}=\mathrm{CM} \times$ menu mix

11. Mengklasifikasi setiap makanan sesuai kategori persentase dari menu mix (MM $\%$ ) yang menunjukan tingkat popularitas menu dan kategori contribution margin (CM) yang menunjukan tingkat keuntungan.

4. Dog (anjing) : low MM\% dan low CM $\mathrm{MM} \%$ dan high $\mathrm{CM}$

2. Plowhorse (kuda) : high $\mathrm{MM} \%$ dan low $\mathrm{CM}$

1. Star (bintang) : high MM\% dan high CM

\section{HASIL DAN PEMBAHASAN}

Berikut hasil analisis menu dengan menggunakan tabel rekayasa menu (menu engineering worksheet), maka makanan- makanan yang dianalisis tersebut dapat dikelompokkan sebagai berikut:

1. Kelompok Bintang (star)

Kelompok Bintang

(star)

merupakan jenis makanan yang memiliki tingkat popularitas tinggi $(\mathrm{H})$ serta memiliki contribution margin yang tinggi $(\mathrm{H})$ pula. Dari 74 makanan yang dianalisis, 22 makanan yang tergolong star atau presentasenya:

22: $74 \times 100 \%=29,73 \%$

2. Kelompok Kuda (Plowhorse) Jenis makanan yang berada dalam kategori Kuda memiliki tingkat popularitas yang tinggi

$(\mathrm{H})$ tetapi kurang memberikan keuntungan (L). Dari 74 makanan yang dianalisis, 19 makanan yang tergolong Plowhorse atau presentasinya:

$19: 74 \times 100 \%=25.68 \%$

3. Kelompok Teka-Teki (Puzzle) Jenis makanan yang berada dalam kategori teka-teki memiliki tingkat popularitas yang rendah $(\mathrm{L})$ tetapi memberikan keuntungan yang tinggi $(\mathrm{H})$. Dari 74 makanan yang dianalisis, 21 makanan yang tergolong puzzle atau presentasinya:

$21: 74 \times 100 \%=28,38 \%$

4. Kelompok Anjing (Dog) Merupakan jenis makanan yang tingkat popularitasnya rendah $(\mathrm{L})$ dan memberikan keuntungan yang rendah pula (L). Dari 74 makanan yang dianalisis, 12 makanan yang tergolong Dog atau presentasenya: $12: 74 \times 100 \%=16.22 \%$

Hasil analisis menu pada Bunut Café dalam bentuk matrix, sebagai berikut: 


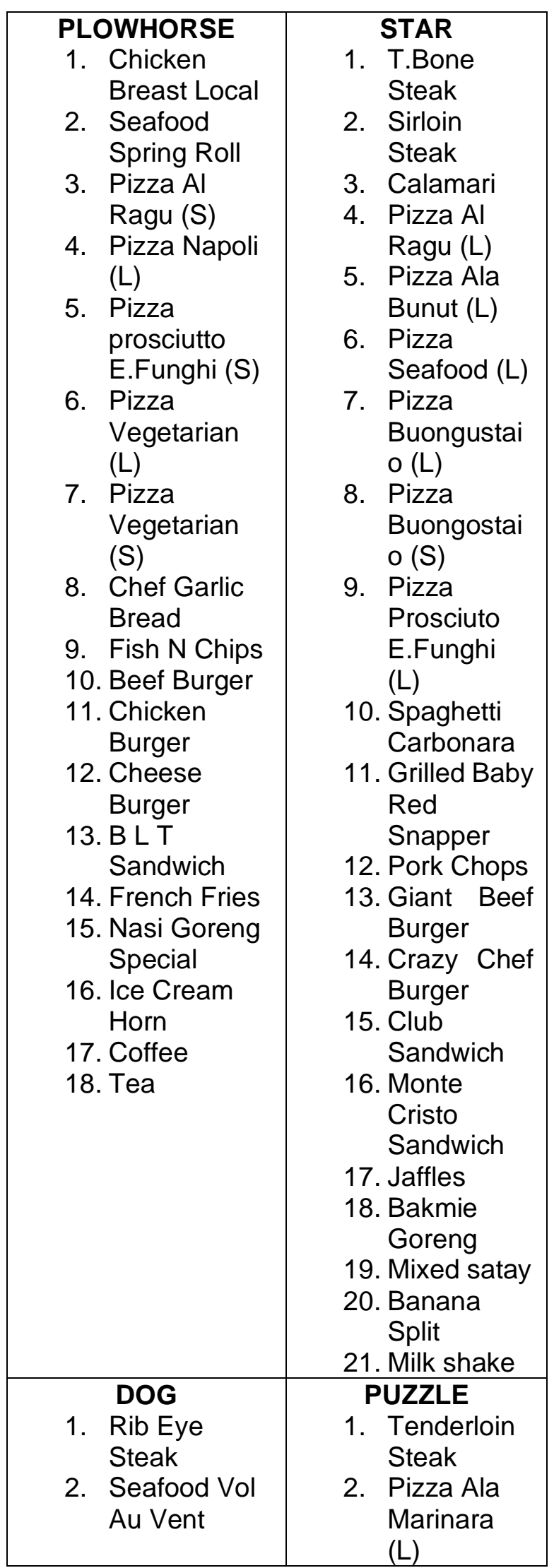

\begin{tabular}{|c|c|}
\hline $\begin{array}{ll}\text { 3. Pizza Ala } \\
\text { Bunut (S) } \\
\text { 4. Pizza } \\
\text { Seafood (S) } \\
\text { 5. Pizza Napoli } \\
\text { (S) } \\
\text { 6. Pizza Earth } \\
\text { Quake (L) } \\
\text { 7. Pizza Earth } \\
\text { Quake (S) } \\
\text { 8. Pizza Ala } \\
\text { Marinara (S) } \\
\text { 9. Pizza Puoco } \\
\text { Diavolo (S) } \\
\text { 10. Tuna Steak } \\
\text { 11. Pork Burger } \\
\text { 12. Steam Rice }\end{array}$ & $\begin{array}{l}\text { 3. Pizza } \\
\text { Puoco } \\
\text { Diavolo (L) } \\
\text { 4. Spaghetti } \\
\text { Seafood } \\
\text { 5. Spaghetti } \\
\text { Bolognaise } \\
\text { 6. Lagsana } \\
\text { 7. Grilled } \\
\text { Fried Prawn } \\
\text { 8. Bebek } \\
\text { Romon } \\
\text { 9hicken } \\
\text { Cordon } \\
\text { Bleu Burger } \\
\text { 10. Tuna } \\
\text { Sandwich } \\
\text { 11. Double } \\
\text { Decker } \\
\text { Sandwich } \\
\text { 12. Hot Dog } \\
\text { 13. Mexican } \\
\text { Hot Dog } \\
\text { 14. Pizza Hot } \\
\text { Dog } \\
\text { 15. Sop Buntut } \\
\text { 16. Ayam } \\
\text { Bakar } \\
\text { 17. White Rose } \\
\text { 18. Rainbow } \\
\text { Parfait } \\
\text { 19. Milk Shake } \\
\text { Float }\end{array}$ \\
\hline
\end{tabular}

Dilihat dari kelas menu hasil analisis, maka tindak lanjut yang harus diambil berkaitan dengan strategi bauran pemasaran yang sebaiknya diambil adalah sebagai berikut:

1. Untuk kategori Star 22 buah $(29,73 \%)$, makanan dengan memiliki keuntungan yang tinggi dan popularitas yang tinggi pula, maka jenis makanan ini hendaknya dipertahankan dan selalu berusaha ditingkatkan volume penjualannya. Untuk itu perlu tindak lanjut sebagai berikut: 
a. Produk (product)

Menjaga dan mempertahankan porsi (volume), kualitas rasa dan penyajian (presentation) dari makanan tersebut.

b. Harga (price)

1) Melakukan peninjauan (survey) terhadap harga bahan makanan secara berkala, dimana nantinya dipakai acuan dalam merevisi harga menu tersebut.

2) Meningkatkan harga jual secara berangsur-angsur, apabila jumlah permintaan mengalami peningkatan

c. Saluran distribusi (place)

Karena menu ini memiliki popularitas yang tinggi, maka pertahankan posisinya pada tempat semula pada bagian menu.

d. Promosi (promotion)

Menurut Tjiptono (2008: 219) pada hakikatnya promosi adalah suatu bentuk komunikasi pemasaran yaitu aktivitas yang berusaha menyebarkan informasi, mempengaruhi/membujuk dan atau mengingatkan pasar sasaran. Meskipun menu ini sangat digemari oleh para konsumen (populer) dan memiliki keuntungan yang tinggi maka diharapkan para pramusaji tidak pernah bosan untuk mengingatkan kepada konsumen yang sudah mengenal makanan ini dan selalu menawarkannya kepada konsumen baru untuk mengoptimalkan keuntungan. Mempromosikan melalui media sosial seperti instagram, facebook dan media lainnya.

\section{PENUTUP}

Hasil dari penelitian ini menunjukan bahwa dari keseluruhan a'la carte menu yang ditawarkan pada Bunut
Café dapat dikategorikan yaitu dari 74 item makanan yang dianalisis, 29,73\% atau 22 item tergolong menu Star (popular dan menguntungkan), $25.68 \%$ atau 19 item menu tergolong kelas menu Plowhorse (popular tetapi tidak menguntungkan), $28.38 \%$ atau 21 item tergolong kelas menu Puzzle (tidak popular tetapi menguntungkan), $16.22 \%$ atau 12 item tergolong kelas menu Dog (tidak popular dan tidak menguntungkan). Strategi bauran pemasaran yang diterapkan oleh pihak manajemen yaitu mempertahankan kualitas makanan, naikkan harga jual jika permintaan menunjukkan peningkatan dan tingkatkan promosi.

\section{DAFTAR RUJUKAN}

Anggayana, I. W. A., \& Sari, N. L. K. J. P. (2018). Kemampuan Berbicara Bahasa Inggris Mahasiswa Akomodasi Perhotelan: sebuah Kajian Fonologi. Jurnal Manajemen Pelayanan Hotel, 1(1), 8-14.

ANGGAYANA, I. W. A., NITIASIH, D. P. K., BUDASI, D. I. G., \& APPLIN, M. E. D. (2016). Developing English For Specific Purposes Course Materials for Art Shop Attendants and Street Vendors. Jurnal Pendidikan Bahasa Inggris Indonesia, 4(1).

Anggayani, N. W., \& Osin, R. F. (2018). Pengaruh Service Performance Terhadap Nilai Sekolah Kepuasan Dan Loyalitas Pelajar Pada Smk Pariwisata Triatma Jaya Tabanan. Jurnal Manajemen Pelayanan Hotel, 1(1), 28-35.

Joko, Tri Haryanto. 2014. Model pengembangan ekowisata dalam mendukung kemandirian ekonomi. Volume 2 No.3,22 Desember 2014. Jurnal Kawistara.

Kotler Philip dan Keller.2007. Manajemen Pemasaran: Analisis, Perencanaan, Implementasi dan Pengendalian. 
Jurnal Manajemen Pelayanan Hotel Akademi Komunitas Manajemen Perhotelan Indonesia (Suryawati \& Osin, halaman 29-35) Vol 3, No 1 Edisi Juni 2019

Edisi Pertama. Penerbit Prentice Hall, Salemba Empat, Jakarta.

Kotler, Philip.2007.Manajemen Pemasaran. Jilid 2, Edisi 12. New Jersey: PT Indeks.

Osin, R. F., Kusuma, I. R. W., \& Suryawati, D. A. (2019). STRATEGI PENGEMBANGAN OBJEK WISATA KAMPUNG TRADISIONAL BENA KABUPATEN NGADA-FLORES NUSA TENGGARA TIMUR (NTT). Jurnal Ekonomi dan Pariwisata, 14(1).

Rabone, Pam.2007. Professional Cookery: Diploma 2. Oxford: Heinemann.

Schwartz, Bill. 2006. A scientific approach to improve menu profitability. (Online). Diakses dari http://www.scribd.com/doc/27892829 /ls-Your-Menu-Working-for-You-orAgainst-You\#scribd. (22 Maret 2015)

Sulastiyono, Agus.2004. Seri Manajemen Usaha Jasa Sarana Pariwisata dan Akomodasi. Manajemen Penyelenggara Hotel.Alfabeta: Bandung.

Tjiptono, Fandy. 2008. Strategi Pemasaran. Edisi Ketiga. Yogyakarta: Andy Offset 